\title{
La aplicación de ivermectina tópica resultó efectiva contra la pediculosis
}

\author{
Topical ivermectin was effective against head lice
}

Pariser DM, et al. NEJM. 2012;367(18):1687-93.

\begin{abstract}
Objetivos
Comparar la efectividad y seguridad de ivermectina contra placebo en el tratamiento de pediculosis.

Diseño

Se reportan los resultados de dos ensayos clínicos de similar diseño (aleatorizados, multicéntricos, y doble ciego) que fueron realizados en paralelo.

\section{Lugar y pacientes}

Cada estudio se realizó en ocho estados de EE.UU. Se incluyeron pacientes sanos mayores de seis meses de edad con infestación activa (en quienes se identificaran tres o más piojos vivos en cabello o cuero cabelludo) y a sus convivientes infestados (quienes presentaran al menos uno o más piojos vivos). Los participantes debían aceptar no utilizar otros tratamientos activos fuera de los investigados. Se definió paciente índice al menor del grupo familiar con infestación activa.
\end{abstract}

\section{Intervención}

El día 1 se instruyó a los pacientes índice a auto-administrarse una única aplicación de ivermectina 0,5\% en loción o placebo (mismo vehículo de la formulación original). El producto debía humedecer todo el cabello y cuero cabelludo durante 10 minutos para luego ser enjuagado. Los días 2, 8 y 15 se evaluó la presencia de piojos, mediante una revisación de al menos 15 minutos (o menor en caso de encontrarse antes un piojo) y se monitorizó la aparición de efectos adversos. Al día 15, se consideró fallido el tratamiento de aquellos pacientes con piojos vivos, a los cuales se les administró un nuevo tratamiento con permetrina $1 \% \mathrm{y} / \mathrm{o}$ extracción de piojos y liendres con peine fino.

\section{Medición de resultados principales}

Pacientes índice libres de piojos al día 2, 8 y 15 (análisis por intención de tratar); y mismo análisis combinando pacientes índice más cohabitantes (análisis por intención de tratar extendido). Reporte de efectos adversos.

\section{Resultados principales}

Entre los dos estudios, se incluyeron 289 pacientes para el análisis por intención de tratar y 781 pacientes para el análisis por intención de tratar extendido.

Los resultados de eficacia para el análisis por intención de tratar se describen en la tabla 1 . Se observaron resultados similares de eficacia al realizar el análisis por intención de tratar extendido.

En cuanto a la seguridad, la aparición de prurito, excoriación y eritema fue menor al $1 \%$ en el grupo ivermectina y resulto mayor al $1 \%$ en el grupo control. Ningún evento adverso se vinculó definitivamente a la droga en estudio. La irritación ocular y la sensación de ardor fueron evaluadas como probablemente relacionados.

El aumento de infestación luego de la aplicación se puede relacionar con otros factores: mala aplicación, falta de exposición de los huevos a la droga o contacto con personas infestadas. También se postula la posible acción de la ivermectina tópica contra los huevos, aunque esta acción no existe con la formulación VO.

Tabla 1: pacientes (\%) libres de piojos según grupo y día de evaluación una vez combinados los resultados de los dos estudios en el grupo de pacientes analizado por intención de tratar.

\begin{tabular}{c|c|c|c}
\hline Día & Grupo ivermectina & Grupo control & p \\
\hline 2 & 131 de $138(94,9 \%)$ & 46 de $147(31,3 \%)$ & 0,001 \\
\hline 8 & 115 de $135(85,2 \%)$ & 30 de $144(20,8 \%)$ & 0,001 \\
\hline 15 & 104 de $141(73,8 \%)$ & 26 de $148(17,6 \%)$ & 0,001 \\
\hline
\end{tabular}

\section{Conclusiones}

Una aplicación única de ivermectina, administrada en forma domiciliaria y durante diez minutos, fue más efectiva que el placebo para eliminar la infestación por piojos al día 1, 7 y 14 posteriores al tratamiento.

Fuente de financiamiento: Sanofi Pasteur.

\section{Comentario}

En este estudio se postula la utilización de ivermectina en forma tópica para el tratamiento de la infestación por piojos, disminuyendo así la tasa de efectos adversos que se observan con la utilización de ivermectina via oral.

La ivermectina administrada vía oral se utiliza para el tratamiento de infestación por nematodes, o ante el fracaso de otros tratamientos anti pediculosis.

La infestación por piojos es causa de estigmatización en niños, ausencias escolares y laborales. Las drogas de primera línea utilizadas son la permetrina y las piretrinas, con las cuales se ha visto aumento de la resistencia. En los últimos años han salido al mercado nuevas drogas, pero dado su mecanismo de acción, estas también se encuentran expuesta a este potencial problema.

\section{Conclusiones del comentador}

El uso tópico de ivermectina resultó efectivo y seguro para el tratamiento de la pediculosis en pacientes mayores de seis meses. Queda pendiente la comparación de efectividad de ivermectina tópica contra las drogas actualmente utilizadas en el mercado y la evaluación de la potencial del desarrollo de resistencia asociado a su uso.

María Victoria Ruiz Yanzi. [ Servicio de Medicina Familiar y Comunitaria del Hospital Italiano de Buenos Aires. mariav.ruiz@hospitalitaliano.org.ar ]

Ruiz Yanzi María Victoria. La aplicación de ivermectina tópica resultó efectiva contra la pediculosis. Evid Act Pract Ambul. 2015:18(1) 6.EneMar.Comentado de: Pariser DM, et al. Topical 0.5\% ivermectin lotion for treatment of head lice. NEJM. 2012;367(18):1687-93. PMID: 23113480. 